\title{
Elevated temperature lasing from injection microdisk lasers on silicon
}

\author{
N V Kryzhanovskaya ${ }^{1,2}$, E I Moiseev ${ }^{1}$, Y S Polubavkina ${ }^{1}$, M V Maximov ${ }^{1,3}$, D V \\ Mokhov $^{1}$, I A Morozov ${ }^{1}$, M M Kulagina ${ }^{3}$, Y M Zadiranov ${ }^{3}$, A A Lipovskii ${ }^{1,2}$, M \\ Tang $^{4}, \mathrm{M} \mathrm{Liao}^{4}, \mathrm{~J} \mathrm{Wu}^{4}, \mathrm{~S} \mathrm{Chen}^{4}, \mathrm{H} \mathrm{Liu}^{4}$ and A E Zhukov ${ }^{1,2}$ \\ ${ }^{1}$ Nanophotonics Lab, St Petersburg Academic University, 194021 St Petersburg, \\ Russia \\ ${ }^{2}$ Peter the Great St Petersburg Polytechnic University, 195251 St Petersburg, \\ Russia \\ ${ }^{3}$ Ioffe Physical Technical Institute of RAS, 194021 St Petersburg, Russia \\ ${ }^{4}$ Department of Electronic and Electrical Engineering, University College London, \\ London WC1E 7JE, UK
}

E-mail: nataliakryzh@gmail.com

\begin{abstract}
A combination of high operation temperatures and small sizes of diode lasers directly grown on silicon substrates is essential for their application in future photonic integrated circuits. In this Letter, results are presented on quantum dot III$\mathrm{V}$-on-Si microdisk diode lasers tested at elevated temperatures. To the best of our knowledge, the first uncooled microlasers with diameter of $30 \mu \mathrm{m}$ capable of operating in continuous wave regime at $60^{\circ} \mathrm{C}$ are demonstrated. In lasing regime, emission spectra contain one most intense line with the full width at half maximum of $30 \mathrm{pm}$; side mode suppression ratio reaches $18 \mathrm{~dB}$. Because of self-heating, an actual temperature of the active region is close to $100^{\circ} \mathrm{C}$. Under pulsed excitation, the maximal lasing temperature is $110^{\circ} \mathrm{C}$.
\end{abstract}

Keywords: Microcavity devices, quantum dots, semiconductor lasers

PACS: 42.55.-f, 78.55.Cr, 78.67. Hc 


\section{Introduction}

Compact size and capability of operation at elevated temperatures facilitate integration of light emitters with silicon-based electronic and photonic elements. Furthermore, a laser heterostructure is preferably to be directly grown on silicon [1]. Microdisk (MD)/microring (MR) lasers are prospective for such integration, since high quality factors can be achieved even in resonators of a few micrometers in diameter $[2,3]$. Suppressed lateral migration of charge carriers along the quantum dot (QD) plane makes QD lasers less sensitive to deep etching [4] and promotes use of QDs in microlasers intended for operation at elevated temperatures [5, 6]. Strong carrier localization within individual QDs is also favorable for their resistance against non-radiative recombination in III-V-on-Si structures. A significant progress has recently been demonstrated in QD structures monolithically grown on Si including realization of edge-emitting lasers [7-11] and optically pumped microlasers [12]. Recently, room temperature (RT) lasing has been achieved in electrically pumped MDs [13] and MRs [14] on Si with the smallest diameter of 14 and $10 \mu \mathrm{m}$, respectively. For larger MR devices (100 $\mu \mathrm{m}$ in diameter) [14], the maximum operation temperature (pulsed and continuous wave $(\mathrm{CW})$ ) of $100^{\circ} \mathrm{C}$ was demonstrated. The lasing spectra of those MRs contain a number of closely spaced modes of comparable intensity within a broad spectral interval from 1.28 to $1.3 \mu \mathrm{m}$.

Devices of smaller size would be helpful for singlemode lasing. However, there are several effects which impede their high temperature operation. First, relative contribution of inevitable non-radiative recombination at sidewalls increases proportionally to the perimeter-to-area ratio. In this respect, a MD laser can be advantageous over a MR one owing to absence of an inner hole. For example, a CW RT threshold current density $\left(J_{\text {th }}\right)$ of $594 \mathrm{~A} / \mathrm{cm}^{2}$ achieved in MDs with diameter of $30 \mu \mathrm{m}$ is only 1.4 times higher than $J_{\text {th }}$ measured in the broad-area laser made of the same QD-on$\mathrm{Si}$ epitaxial structure [13]. Second, self-heating is expected to be more significant in smaller lasers because of hindered heat dissipation. In comparison with a MR laser of the same diameter, a MD laser has larger area of its contact with substrate, which is beneficial for lower thermal resistance. Specific thermal resistance of $4{ }^{\circ} \mathrm{C} \times \mathrm{cm}^{2} / \mathrm{mW}$ was found in QD-on-Si MD lasers with diameters from 14 to $30 \mu \mathrm{m}$ [13].

In this article, we report on uncooled operation of QD-on-Si MD lasers at elevated temperatures. Lasing was achieved under $\mathrm{CW}$ and pulsed excitation up to 60 and $110^{\circ} \mathrm{C}$, respectively, in MDs with diameter of $30 \mu \mathrm{m}$. These are the smallest microlasers on silicon operating at these elevated temperatures. Nearly single mode emission is demonstrated with a dominant mode linewidth as narrow as $30 \mathrm{pm}$. Up to $90^{\circ} \mathrm{C}$ lasing proceeds on the ground state (GS) optical transition of QDs with wavelength about $1.35 \mu \mathrm{m}$. At higher temperatures, lasing wavelength jumps to $1.3 \mu \mathrm{m}$ that corresponds to the excited state (ES) transition.

\section{Methods}

A III-V epitaxial structure was grown by molecular beam epitaxy on a silicon (001) substrate with $4^{\circ}$ offcut to the [011] plane. Upon oxide desorption, a 30-nm AlAs nucleation layer, a 570-nm GaAs buffer layer, an $\mathrm{Al}_{0.4} \mathrm{Ga}_{0.6} \mathrm{As} / \mathrm{GaAs}$ superlattice (SL) of $200 \mathrm{~nm}$, and a $100 \mathrm{~nm}$ GaAs buffer layer were deposited followed by $n$-type doped $\mathrm{InGaAs} / \mathrm{GaAs}$ dislocation filter layers (DFL) [15] of total thickness of $1.7 \mu \mathrm{m}$. An AlGaAs/GaAs laser heterostructure grown on the top of the DFL consists of a $1.4 \mu \mathrm{m} \mathrm{n}-\mathrm{Al}_{0.4} \mathrm{Ga}_{0.6} \mathrm{As}$ lower cladding layer, an undoped $\mathrm{GaAs}$ waveguiding layer, a $1.4 \mu \mathrm{m} p-\mathrm{Al}_{0.4} \mathrm{Ga}_{0.6} \mathrm{As}$ upper cladding layer, and a $0.3 \mu \mathrm{m} p^{+}$-GaAs contacting layer with four shortperiod $\mathrm{Al}_{0.4} \mathrm{Ga}_{0.6} \mathrm{As} / \mathrm{GaAs}$ SLs inserted at interfaces. An active region represents 7 layers of InAs/InGaAs dot-in-well structures [16] separated by $38.5 \mathrm{~nm}$ GaAs spacers. Total thickness of the vertical waveguide is about $0.4 \mu \mathrm{m}$. Scanning electron microscopy (SEM) image of the structure cross-section (the left panel of figure 1) reveals good interface planarity and absence of microcracks. 


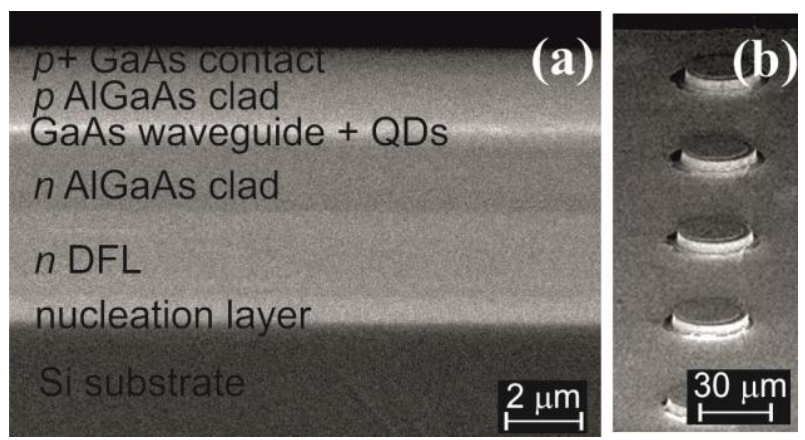

Figure 1. SEM images of cross section view of the epitaxial structure (a) and axonometric view of five 30- $\mu$ m microdisks (b).

The structure was processed into an array of $4.5-\mu \mathrm{m}$ tall MDs [6] with diameter of $30 \mu \mathrm{m}$ (the right panel of figure 1) using photolithography and inductively coupled $\mathrm{BCl}_{3} / \mathrm{Ar}$ plasma dry etching process. No sidewall coating or passivation was applied. Individual circular-shaped $\mathrm{AgMn} / \mathrm{NiAu} p$ ohmic contacts were placed on top of the MDs and a common $\mathrm{AuGe} / \mathrm{Ni} / \mathrm{Au} n$-ohmic contact was deposited onto the etched surface between the MDs. MD lasers were put onto a copper holder, which temperature was varied by a heater from RT (about $25^{\circ} \mathrm{C}$ ) to $110^{\circ} \mathrm{C}$.

Microlaser characteristics were measured in $\mathrm{CW}$ and pulsed regimes. In the latter case, we used 0.5 - $\mu$ s-long injection pulses with $10 \mathrm{kHz}$ repetition rate. The MDs were electrically pumped using needle probes. DC current was varied from 0 to $25 \mathrm{~mA}$. In pulsed regime, injection current was limited at $300 \mathrm{~mA}$. A turn-on voltage of $1.6 \mathrm{~V}$ and a series resistance of $40 \mathrm{Ohm}$ were derived from the current-voltage curves (5-20 mA) taken at RT. An adjustable infrared objective with x10 magnification was used to collect light emitted from an individual microlaser. Emission spectra were acquired with spectral resolution of $\sim 30$ pm using a Horiba FHR 1000 monochromator and an InGaAs CCD array.

\section{Results and discussion}

An emission spectrum of a MD contains a series of nearly equally spaced sharp lines which are attributed to whispering gallery modes of different azimuthal orders. A representative $\mathrm{CW}$ spectrum measured at $17 \mathrm{~mA}$ current and the holder temperature of $60^{\circ} \mathrm{C}$ is depicted in figure 2 . As argued below, this injection current is beyond the lasing threshold estimated as $15 \mathrm{~mA}$ for these operation conditions. The most intense (dominant) mode is located at $1362.2 \mathrm{~nm}$. It is much brighter than the background electroluminescence in the whole interval of spontaneous emission. The neighboring longer-wavelength (side) mode $(\lambda=1367.5 \mathrm{~nm})$ is more than one order of magnitude less intense in comparison with the dominant one. Other modes are hardly seen since they are one more order of magnitude less intense. High purity of emission spectrum distinguishes the MD lasers under study from recently demonstrated MR lasers on silicon, ${ }^{14}$ where a plurality of modes of comparable intensity is observed. 


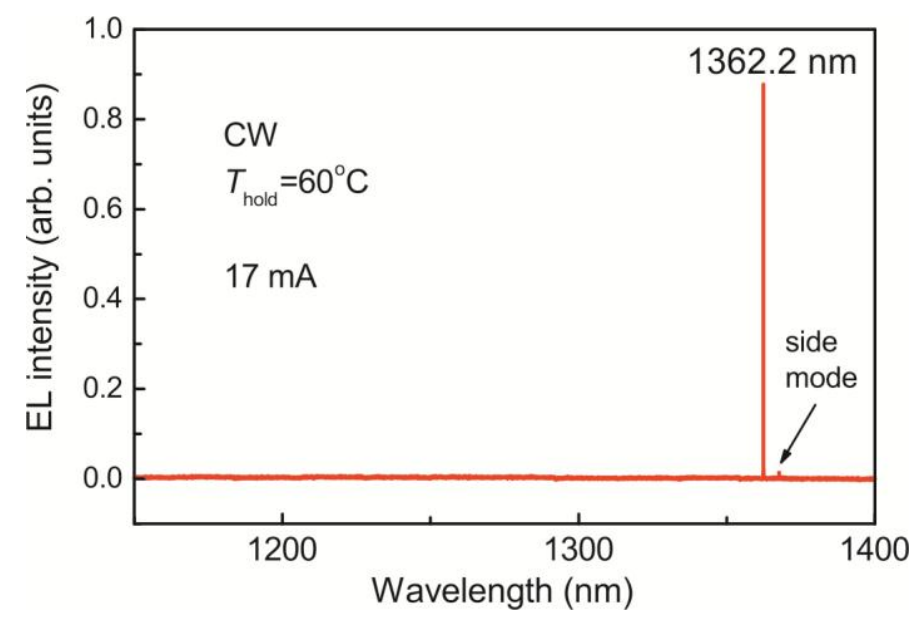

Figure 2. Overall emission spectrum obtained at $17 \mathrm{~mA}$.

Figure 3 depicts in detail those parts of the spectrum where the dominant and side modes are located. The data are presented for injection current varied around the threshold, from 14.5 to 16 $\mathrm{mA}$. As current increases in this interval, intensity of the side mode remains nearly unchanged whereas the dominant mode demonstrates a rapid growth. The side mode suppression ratio (SMSR), which is defined as peak-to-peak ratio of the dominant mode to the side one, reaches its maximal value of $17.8 \mathrm{~dB}$ at $17 \mathrm{~mA}$. The cavity resonances are shifted to longer wavelengths as injection current increases. In $\mathrm{CW}$ regime, the mode redshift is caused by self-heating of the uncooled device. Spectral positions of the dominant and side modes against injection current are presented in the inset of figure 3. For both modes, the slope $(\mathrm{d} \lambda / \mathrm{d} I)$ of $0.144 \mathrm{~nm} / \mathrm{mA}$ was derived. This corresponds to a current induced temperature increment $(\mathrm{d} T / \mathrm{d} I)$ of $1.77{ }^{\circ} \mathrm{C} / \mathrm{mA}$ taking into account a temperature coefficient $(\mathrm{d} \lambda / \mathrm{dT})$ of $81.5 \mathrm{pm} /{ }^{\circ} \mathrm{C}[6]$. An actual temperature of the MD laser was then calculated by adding the temperature increment to the holder temperature (the inset of figure 3). It is seen that the actual temperature can reach $100^{\circ} \mathrm{C}$ at the maximal current used $(25$ $\mathrm{mA}$ ). At threshold, the device is additionally heated by approximately $26^{\circ} \mathrm{C}$.

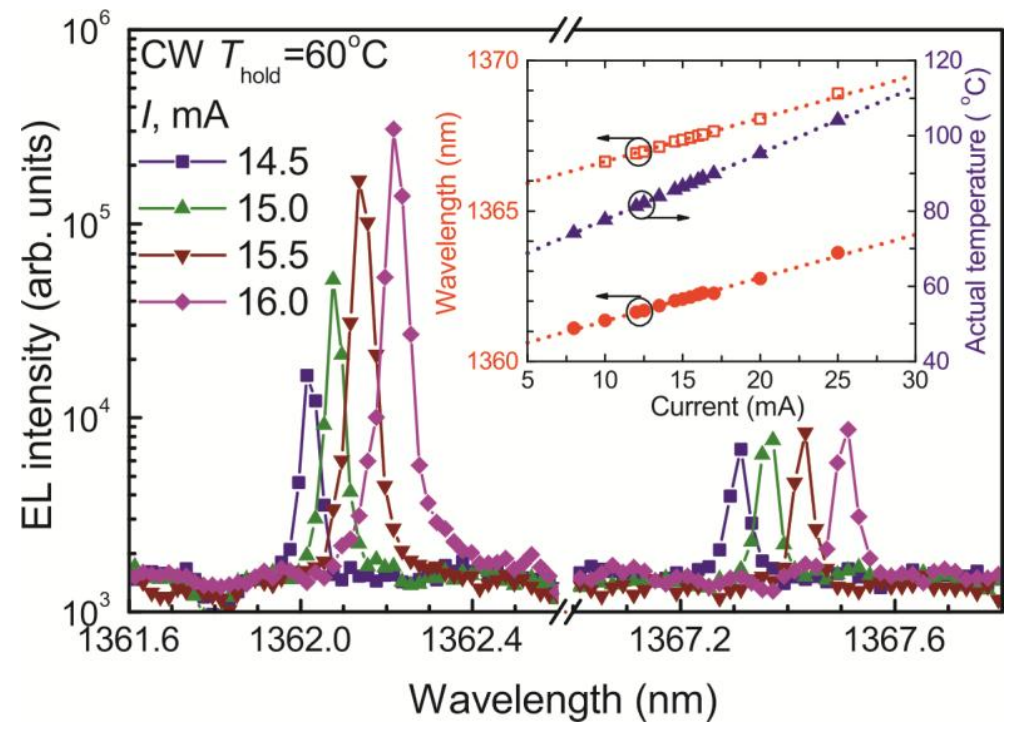

Figure 3. Close-up spectra (logarithmic scale) taken at $60^{\circ} \mathrm{C}$ and different injection currents. Inset: Current-induced variation of spectral positions of the dominant (circles) and side (squares) modes measured at holder temperature of $60^{\circ} \mathrm{C}, \mathrm{CW}$ regime. Triangles: estimated actual temperature of MD. Dashed curves: linear fits. 
Realization of $\mathrm{CW}$ lasing at $60^{\circ} \mathrm{C}$ is confirmed by dependences of the dominant mode integrated intensity, linewidth and SMSR on injection current (figure 4). The light-current curve reveals a pronounced knee. The linewidth simultaneously drops down to the spectral resolution limit, and a rapid growth of SMSR takes place. We estimated the threshold current $I_{\text {th }}$ as $15 \mathrm{~mA}$, which corresponds to $J_{\text {th }}$ of $2.1 \mathrm{kA} / \mathrm{cm}^{2}$. As injection current increases beyond $17 \mathrm{~mA}$, SMSR starts decreasing and even changes its sign. This is accompanied by a decay of the mode intensity and some broadening of the line. All these observations reflect the fact that the longer-wavelength mode $(\lambda=1367.5 \mathrm{~nm})$ becomes the dominant one. Similar behavior is also observed at lower temperatures. The lower is temperature the larger is interval of injection current in which a certain lasing mode persists.

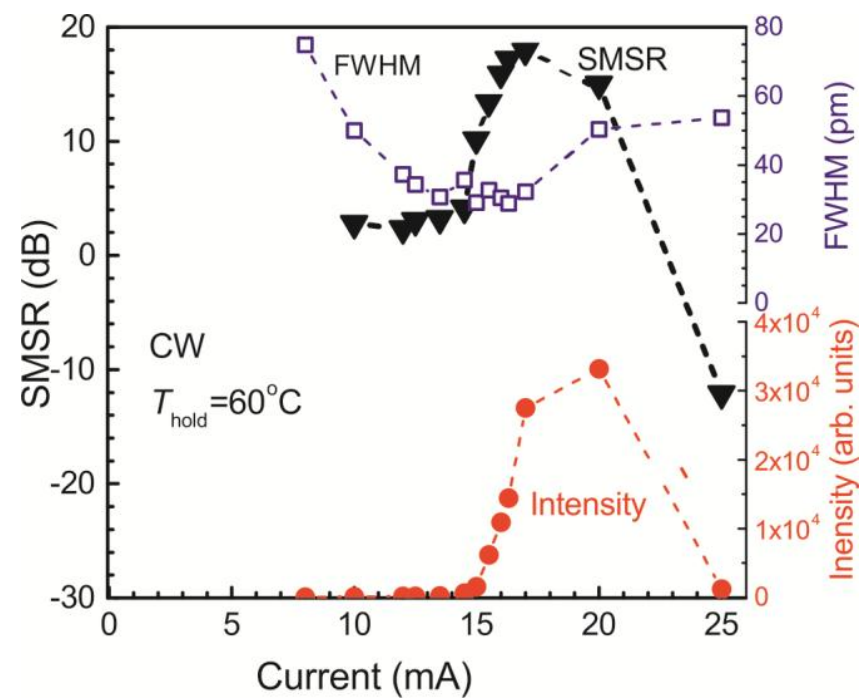

Figure 4. SMSR (triangles), FWHM (squares), and integrated line intensity (circles) of the dominant mode $(\lambda=1362.2 \mathrm{~nm})$ as functions of injection current in $\mathrm{CW}$ regime at $60^{\circ} \mathrm{C}$.

The figure 5 shows log-log plot of the dominant mode intensity as a function of injection current at RT, $45^{\circ} \mathrm{C}$ and $60^{\circ} \mathrm{C}$. All the dependences show a characteristic S-shape indicating the transition from spontaneous to lasing regime of emission [17]. As holder temperature increases, $I_{\text {th }}$ shifts to higher values. Meanwhile, at $75^{\circ} \mathrm{C}$ the dominant mode does not anymore demonstrate a rapid growth, and its intensity remains low with increase in injection current. The maximal temperature, at which CW lasing is achieved in these QD microdisk lasers on silicon, is $60^{\circ} \mathrm{C}$. To the best of our knowledge, this is the highest $\mathrm{CW}$ operation temperature of any III-V microlasers directly grown on silicon and having a microlaser lateral size of few tens of micrometers. 


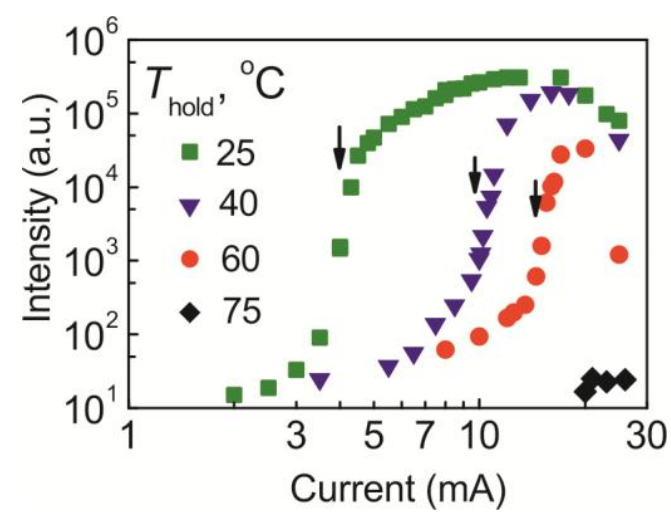

Figure 5. Integrated intensity of the dominant modes at different holder temperatures (squares $25^{\circ} \mathrm{C}$, triangles $45^{\circ} \mathrm{C}$, circles $60^{\circ} \mathrm{C}$, rhombs $75^{\circ} \mathrm{C}$ ). Arrows indicate threshold current values where applicable.

Figure 6 summarizes the minimal $J_{\text {th }}$ measured at different holder temperatures in $\mathrm{CW}$ and pulsed regimes. At RT, the threshold current is $4.2 \mathrm{~mA}\left(J_{\mathrm{th}}=0.59 \mathrm{kA} / \mathrm{cm}^{2}\right)$ in $\mathrm{CW}$ and $3.8 \mathrm{~mA}\left(J_{\text {th }}\right.$ $\left.=0.54 \mathrm{kA} / \mathrm{cm}^{2}\right)$ in pulsed mode. The maximal temperature, at which lasing was realized, is limited by our experimental setup, $110^{\circ} \mathrm{C}$, with $J_{\text {th }}$ of $13.45 \mathrm{kA} / \mathrm{cm}^{2}$. Spectral positions of the dominant modes taken at the thresholds are shown in figure 6 together with wavelengths of the GS and ES optical transitions of QDs. It is seen that up to $90^{\circ} \mathrm{C}$ lasing proceeds within the GS transition; the wavelength is around $1.35 \mu \mathrm{m}$. The spectral positions of the lasing mode measured at 100 and $110^{\circ} \mathrm{C}$ are significantly shifted to a shorter wavelength $(\sim 1.3 \mu \mathrm{m})$ that corresponds to the ES transition. This indicates that the maximal gain achievable at the GS transition is insufficient to balance optical loss at sufficiently high temperatures. We suggest that additional optical loss at high temperatures is caused by enhanced free carrier absorption in the laser waveguiding layer.

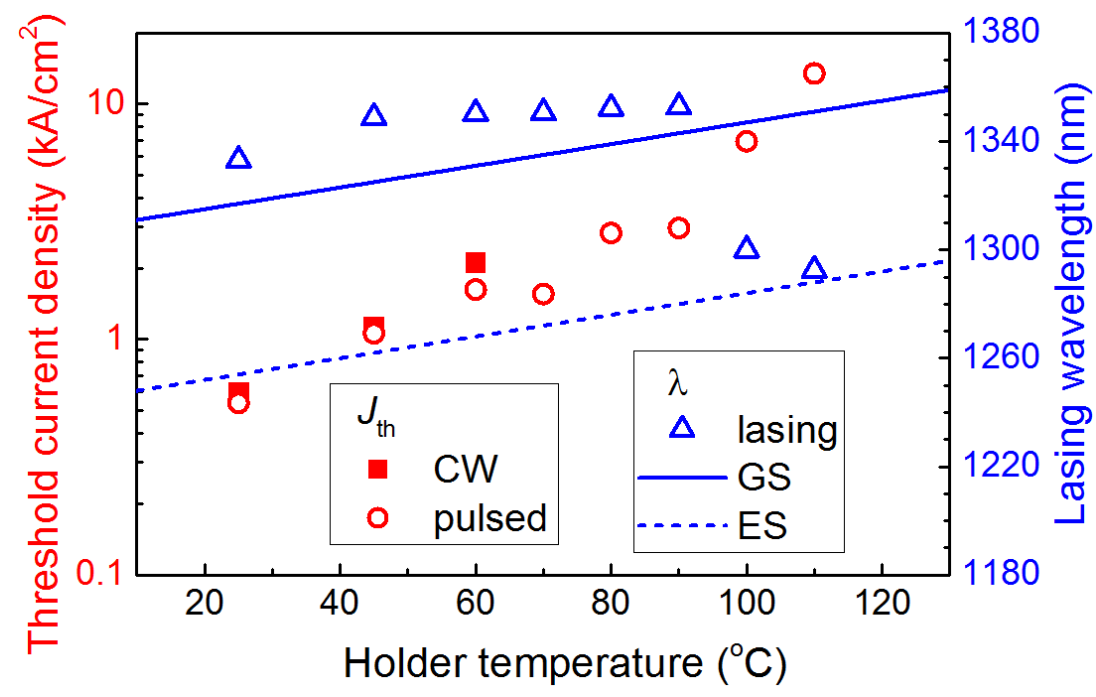

Figure 6. Temperature dependences of threshold current densities in $C W$ (squares) and pulsed (circles) regimes, spectral positions of lasing wavelength (triangles), ground-state (solid line) and excited-state (dashed line) QD emission maxima. 


\section{Conclusion}

In summary, we examine uncooled QD-based microdisk lasers on silicon at elevated temperatures. We demonstrate, for the first time, lasing operation of $30-\mu \mathrm{m}$ in diameter microlasers at $60^{\circ} \mathrm{C}$ in $\mathrm{CW}$ and $110^{\circ} \mathrm{C}$ in pulsed mode. Under these operation conditions (excepting $100-110{ }^{\circ} \mathrm{C}$ ), lasing wavelength is well beyond $1.3 \mu \mathrm{m}$ being within the GS optical transition. As holder temperature reaches $100^{\circ} \mathrm{C}$, lasing wavelength switches to the ES transition $(\sim 1.3 \mu \mathrm{m})$. In $\mathrm{CW}$ lasing regime, the $\lambda / \Delta \lambda$ ratio exceeds 45000 . At the maximal temperature of $\mathrm{CW}$ operation lasing spectrum remains nearly singlemode with the dominant mode to the side mode intensity ratio about $18 \mathrm{~dB}$.

\section{Acknowledgments}

This work was supported by the Russian Foundation for Basic Research (grants \# 16-29-03037, 1629-03111, 18-02-00541), Russian Ministry of Education and Science (grant \# 3.9787.2017/8.9) and by UK EPSRC under Grants EP/J012904/1, EP/K029118/1, and EP/P006973/1.

\section{References}

[1] Cornet C, Léger Y and Robert C 2016 Integrated Lasers on Silicon (ISTE Press - Elsevier). https://www.elsevier.com/books/integrated-lasers-on-silicon/cornet/978-1-78548-062-1

[2] Srinivasan K, Borselli M, Painter O, Stintz A and Krishna S 2006 Opt. Express 141094.

[3] Kryzhanovskaya N V, Zhukov A E, Maximov M V, Moiseev E ., Shostak I I, Nadtochiy A M, Kudashova Yu V, Lipovskii A A, Kulagina M M, and Troshkov S I 2015 IEEE J. Selected Topics Quantum Electron. 211900905.

[4] Ouyang D, Ledentsov N N, Bimberg D, Kovsh A R, Zhukov A E, Mikhrin S S, and Ustinov V M 2003 Semicond. Sci. Technol. 18 L53.

[5] Munsch M, Claudon J, Malik N S, Gilbert K, Grosse P, Gérard J-M, Albert F, Langer F, Schlereth T, Pieczarka M M, Höfling S, Kamp M, Forchel A, and Reitzenstein S 2012 Appl. Phys. Lett. 100031111.

[6] Kryzhanovskaya N V, Moiseev E I, Kudashova Yu V, Zubov F I, Lipovskii A A, Kulagina M M, Troshkov S I, Zadiranov Yu M, Livshits D A, Maximov M V, and Zhukov A E 2015 Electron. Lett. 511354.

[7] Wang T, Liu H, Lee A, Pozzi F, and Seeds A 2011 Opt. Express 1911381.

[8] Lee A, Jiang Q, Tang M, Seeds A, and Liu U 2012 Opt. Express. 20, 22181.

[9] Lee A D, Jiang Q, Tang M, Zhang Y, Seeds A J, and Liu H 2013 IEEE J. Selected Topics Quantum Electron. 191901107.

[10] Liu A Y, Zhang C, Norman J, Snyder A, Lubyshev D, Fastenau J M, Liu A W K, Gossard A C, and Bowers J E 2014 Appl. Phys. Lett. 104041104.

[11] Chen S, Li W, Wu J, Jiang Q, Tang M, Shutts S, Elliott S N, Sobiesierski A, Seeds A J, Ross I, Smowton P M, and Liu H 2016 Nat. Photon. 10307.

[12] Wan Y, Li Q, Liu A Y, Gossard A C, Bowers J E, Hu E, and Lau K M 2016 Opt. Lett. 41 1664.

[13] Kryzhanovskaya N V, Moiseev E I, Polubavkina Yu S, Maximov M V, Kulagina M M, Troshkov S I, Zadiranov Yu M, Guseva Yu A, Lipovskii A A, Tang M, Liao M, Wu J, Chen S, Liu H, and Zhukov A E 2017 Optics Letters, 42, 3319. 
[14] Wan Y, Norman J, Li Q, Kennedy M J, Liang D, Zhang C, Huang D, Liu A Y, Torres A, Jung D, Gossard A C, Hu E L, Lau K M, and Bowers J E 2017 CLEO: Applications and Technology (San Jose, CA, USA, 14-19 May 2017).

[15] Tang M, Chen S, Wu J, Jiang Q, Kennedy K, Jurczak P, Liao M, Beanland R, Seeds A J, and Liu H 2016 IEEE J. Selected Topics Quantum Electron. 22, 1900207.

[16] Liu H Y, Sellers I R, Badcock T J, Mowbray D J, Skolnick M S, Groom K M, Gutiérrez M, Hopkinson M, Ng J S, David J P R, and Beanland R 2004 Appl. Phys. Lett. 85, 704.

[17] Jaffrennou P, Claudon J, Bazin M, Malik N S, Reitzenstein S, Worschech L, Kamp M, Forchel A, and Gérard J-M 2010 Appl. Phys. Lett. 96, 071103. 